NASA

Technical Memorandum 83669

AIAA-84-1297

N $84-2564 \bar{y}$

USAAVSCOM

Technical Report 84-C-1

\title{
Application of a Quasi-3D Inviscid Flow and Boundary Layer Analysis to the Hub-Shroud Contouring of a Radial Turbine
}

Kestutis C. Civinskas

Propulsion Laboratory

AVSCOM Research and Technology Laboratories

Lewis Research Center

Cleveland, Ohio

and

Louis A. Povinelli

Lewis Research Center

Cleveland, Ohio

Prepared for the

Twentieth Joint Propulsion Conference

cosponsored by the AIAA, SAE, and ASME

Cincinnati, Ohio, June 11-13, 1984

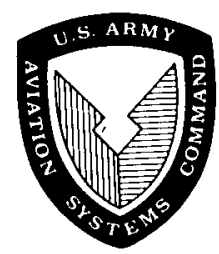


APPLICATION OF A QUASI-3D INVISCID FLCW AND BOUNDARY LAYER ANALYSIS

TO THE HUB-SHROUD CONTOURING OF A RADIAL TURBINE

\author{
Kestutis C. Civinskas \\ Propulsion Laboratory \\ AVSCOM Research and Technology Laboratories \\ Cleveland, Ohio \\ and \\ Louis A. Povinelli \\ National Aeronautics and Space Administration \\ Lewis Research Center \\ Cleveland, Ohio
}

\section{Abstract}

Application of a quasi-30 approach to the aerodynamic analys is of several radial turbine configurations is described. The objective was to improve the rotor aerodynamic characteristics by hub-shroud contouring. The approach relies on available 20 inviscid methods coupled with boundary layer analysis to calculate profile, mixing, and endwall losses. Windage, tip clearance, incidence, and secondary flow losses are estimated from correlations. To eliminate separation along the hub and blade suction surfaces of a baseline rotor, the analysis was also applied to three alternate hub-shroud geometries. Emphasis was on eliminating an inducer velocity overshoot as well as increasing hub velocities. While separation was never eliminated, the extent of the separated area was progressively reduced. Results are presented in terms of mid-channel and blade surface velocities; kinetic energy loss coefficients; and efficiency. Geometries illustrated are not an exhaustive attempt at design optimization. The calculation demonstrates a first step for a systematic approach to radial turbine design that can be used to identify and control aerodynamic characteristics that ultimately determine heat transfer and component life. Experimentation will be required to assess the extent to which flow and boundary layer behavior were predicted correctly.

\section{Nomenc 1 ature}

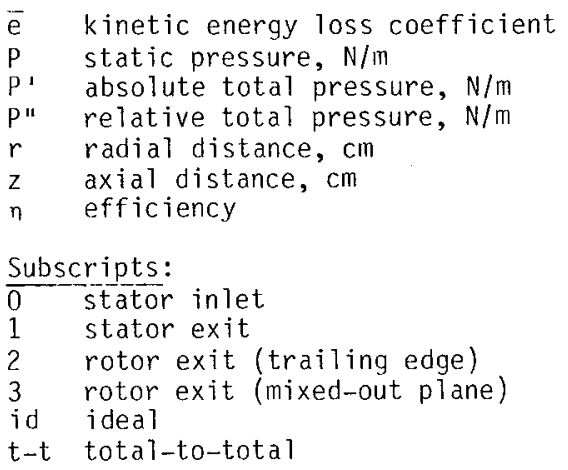

\section{Introduction}

The radial turbine continues to be a candidate component for small gas turbine engines because of its high stage work and potential efficiency advantage over the axial turbine. Past efforts aimed at describing the characteristifs of radial turbines include the work by Balje ${ }^{1}$ who described their performance in terms of Mach number, Reynolds number specific diameter, and specific speed. Benson ${ }^{2}$ followed a similar approach but refined some of the geometry characteristics to include inlet and outlet blade height and nozzle and rotor exit angles. Watanabe ${ }^{3}$ experimentally examined effects of the vaneless space gap, the area ratio between impeller inlet and exit, rotor inlet to exit diameter ratio, and clearance. Mizumachi ${ }^{4}$ experimentally studied the effect of blade number and exducer blade angle. From measurements of flow angle and velocity coefficient, he inferred what was happening inside the rotor passage regarding secondary flows and separation. In general, these and other efforts in radial turbine performance characterization have been limited to overall flow conditions into and out of the turbine and have not addressed the flow inside the blading. For many practical applications, this is perfectly adequate.

For high-temperature, highly-stressed applications, however, the radial turbine's acceptance has been delayed because of the difficulties associated with fabricating a cooled rotor that satisfies life requirements. A significant part of these difficulties can be traced to a lack of basic understanding of the boundary layer behavior through the rotor passage. The lack of a systematic approach for even the aerodynamic calculations aggravates an already difficult heat transfer and cooling design problem. The resultant uncertainty in rotor aerothermodynamics has made radial turbine design as much an art as it is a science, with each designer relying heavily on some unique past experience.

This paper describes the application and results of a systematic quasi-3D approach to the aerodynamic analys is of several radial turbine configurations. The objective was to improve the aerodynamic characteristics of the rotor by hubshroud contouring. Overall losses were estimated in all cases, but since no experimental data were available, a comparison with data could not be made. The approach was to use the coupled MERIDL, TSONIC, and BLAYER computer code described in Ref. 5. These three codes have been coupled and linked with a loss analysis model which has been shown to agree well with experimental data for axial turbines. In the present effort, the same analysis, with some minor modifications, was applied to four radial rotor configurations. The baseline configuration is an early version of a $20 \mathrm{~cm}$ cooled radial research turbine designed for an advanced rotorcraft application of $1607 \mathrm{~K}$ inlet temperature and a work output of $465 \mathrm{~J} / \mathrm{g}$. Because of a large predicted separation on the hub and

This paper is declared a work of the U.S.

Government and therefore is in the public domain. 
suction surfaces of the baseline rotor, an attempt was made to minimize or eliminate the diffusion by hub-shroud contouring. While holding the stator geometry unchanged, three alternate rotors with varying hub-shroud contours were analyzed. Blade number and blade geometry were held fixed. Results are presented in terms of mid-channel velocity profiles, blade surface loadings, extent of separation, efficiency, and kinetic energy loss coefficients.

\section{Method/Approach}

The analysis approach used in this paper is essentially the one presented by Boyle, Haas, and Katsanis in Ref. 5. The analysis procedure is applied to both stator and rotor and is iteratively coupled to the calculated losses. First, the inviscid two-dimensional computer program MERIDL is used to calculate the flow velocities on the hubto-tip midchannel stream surface with an assumed pressure drop due to losses. The resultant streamsheet thicknesses are subsequently used in the TSONIC program to obtain solutions on five bladeto-blade stream surfaces from hub-to-tip. The pressure and suction surface exit static pressures are made equal for each TSONIC solution by adjusting the downstream whirl distribution for the MERIDL program. This iteration is repeated unti] the static pressures are equal within some tolerance limit. The resulting quasi-3D solution of the flow through the passage serves as input for the integral method boundary layer code BLAYER to compute the boundary layer growth along pressure, suction, and endwall surfaces. Profile, mixing, and endwall losses are determined from boundary layer parameters using Stewart's analys is. ${ }^{6}$. Empirical models are used to account for incidence, disc cavity, rotor tip clearance, and secondary flow losses. A mass-averaged overall loss is calculated and an equivalent pressure drop is determined. The newly calculated pressure drop replaces the initially guessed value in MERIDL and the entire procedure is repeated until the two values agree within some tolerance limit.

Except for some minor modifications to account for the radial geometry, the empirical loss models used were generally the same as those described in Ref. 5. The few exceptions can be summarized as follows. The same secondary loss correlations were used, but with the original authors' coefficients 7,8 in the secondary loss equation. Since endwall losses are computed independently, only the leading edge vortex term was retained. Since the tip clearance model used in Ref. 5 accounted only for radial clearance in an axial turbine, the results from Ref. 9 were used to obtain an effective clearance that accounted for both axial and radial clearances found in a radial turbine. An optimum incidence angle for the radial rotor was determined from the slip factor correlations developed by Wiesner in Ref. 10. The incidence loss was then calculated from the deviation angle as in Ref. 5 . The disc cavity loss model of Ref. 5 was used but with a reduced rim radius to simulate a scalloped backface for the radial rotor.

Some notes are also in order regarding the boundary layer analysis. The BLAYER code has been revised to include the effect of radius change. For the present analysis, the boundary layer was assumed to be entirely turbulent and no laminar solution was calculated. Small initial displacement and momentum thicknesses were specified. The separation criteria was skin friction coefficient becoming zero or negative. In cases where separation did occur, the smoothing feature in BLAYER was first used to locally smooth the free-stream velocity solutions obtained from TSONIC. If the separation persisted after a specified number of smoothings, a BLAYER solution would be generated for a revised velocity distribution that eliminated surface diffusion entirely. As applied to the blade suction surface at the hub, the revised velocity distribution would retain the strong acceleration found near the trailing edge and would simply maintain a constant minimum velocity over the forward portion of the blade. The inherent assumption is that this revised solution is indicative of a boundary layer thickness at the trailing edge if the flow re-attached after an initial separation. Since there is no penalty applied to cases that separate and re-attach, it is probably not very meaningful to compare such cases on calculated efficiency alone. In such cases, however, the analysis still provides guidance as to the presence and extent of the separation.

\section{$\underline{\text { Results }}$}

\section{Baseline Rotor Configuration}

Design requirements. - The turbine design requirements are suminarized in Table I. Size, work, and inlet conditions are representative of a high-pressure gas-generator turbine for an advanced rotorcraft application. The meridional flowpath of the complete stage is shown in Fig. 1(a). There are 15 stator vanes and 14 rotor blades. The stator exit flow angle was approximately $75^{\circ}$. The inducer was not swept and the rotor blading had structurally radial blade elements. The blading profiles were intended to accomodate cooling and reflect thickness distributions based on stress considerations. A center bore through the rotor hub was included to allow passage of an output power shaft. This design feature impacted the bore stresses considerably and dictated a maximum radius of about $5.6 \mathrm{~cm}$ for the solid material portion of the hub.

Mid-channel velocities. - Figure 1 (b) shows the MERIDL orthogona? mesh used for the baseline geometry flow analysis. Mid-channel velocities calculated along five streamlines are shown in Fig. 2. In the inducer entrance region, the flow rapidly accelerates as the area decreases with radius in the streamwise direction. As the hub and shroud contours begin to diverge and also turn axially, the streamwise area variation reverses and the flow experiences a strong deceleration. This deceleration is most pronounced along the hub streamline. In the exducer region, where the blade turning decreases the relative throughflow area, the flow is strongly re-accelerated.

Blade surface velocities. - The resulting blade surface velocities along hub, mean, and tip streamlines are shown in Fig. 3 for the baseline rotor. As anticipated, the mid-channel diffusions are further accentuated on the blade suction surfaces, particularly in the hub region.

Boundary layer. - A BLAYER analys is of the baseline rotor blade pressure and suction velocities was done for five hub-to-tip streamlines. 
Using the hub TSONIC solution, a BLAYER analysis was also done for five streamlines along the hub endwall. Figure 4 shows the blade suction and hub endwall surfaces in nondimensional form as stream function and streamwise distance. The shaded area represents the approximate extent of the separated region for the baseline configuration. Separation was predicted by BLAYER when skin friction coefficient went to zero or negative. For all the cases along streamlines that separated, revised solutions, as explained earlier, were obtained. The re-attachment point was taken to be where the momentum thickness began to decrease in the revised solution. As indicated in the figure, flow separation for the baseline rotor occurred on the blade suction surface from the hub up to 25 percent span. Separation also occurred on the hub endwall from the blade suction surface to the 75 percent streaml ine.

\section{Contoured Hub-Shroud Configurations}

Geometry. - In an attempt to minimize or eliminate the relatively large separation region in the baseline rotor, three alternate rotor configurations were similarly analyzed. In each case, only the hub and shroud contours were varied and the same input blade sections were used to generate the actual blading within the 1 imits of those contours. The stator was left unchanged. The emphasis in each case was on eliminating or minimizing the initial overacceleration of the midchannel velocity in the inducer region as well as increasing the minimum velocity along the hub. The $5.6 \mathrm{~cm}$ maximum radius for the solid hub portion was kept as an anchor for all the alternate hub contours. Figures 5 to 7 show the three alternate hub-shroud geometries. Part (a) of each figure shows the alternate contour compared to the baseline and part (b) shows the resulting MERIDL mesh. The contour A geometry in Fig. 5 has two modifications to the shroud contour. To compensate for the rapid flow acceleration in the inducer region, the flow area in that region was increased by modifying the shroud contour. To increase the minimum flow velocities along the hub, the entire exit flow area was reduced by decreasing the exducer tip diameter. In addition to these shroud changes, the contour $B$ geometry shown in Fig. 6 incorporates hub contour changes to further increase and decrease the flow areas in the inducer and exducer regions, respectively. The contour $C$ geometry shown in $F i g .7$ has one additional modification to the exducer shroud contour to further increase the minimum velocity along the hub.

Mid-channel velocities. - The impact of the various hub-shroud contour changes on the midchannel velocities can be seen in Figs. 8 to 10 . The inducer shroud changes of contour A (fig. 8) decreased the initial velocity overshoot and the additional contouring of the inducer hub in contour B (fig. 9) all but eliminated it. The improved reaction with reduced exit area raised the minimum velocities along the hub for all the alternate configurations. The exducer hub contour of rotor $B$ ( $f$ ig. 9) and the exducer tip contour on configuration $C$ (fig. 10), each increased the minimum hub velocities further. It should be noted that the variations in mid-channel exit velocities are not simply due to continuity responding to area changes alone. Closure of the blade loading at the trailing edge was achieved at five radial locations for each rotor by varying the radial work distribution.
Stage pressure ratios, therefore, were not identi$\mathrm{Cal}$ and the converged solutions for rotor contours $A, B$, and $C$ had work levels 5.4, 5.3, and 7.9 percent higher than the baseline rotor, respectively (see bottom of Table II). Another level of iteration involving rotor blade geometry variation would have been necessary to achieve identical work levels.

Blade surface velocities. - The corresponding blade surface velocities for the contoured rotors at the hub, mean, and tip sections are shown in Figs. 11 to 13 . The trends that were observed in mid-channel velocities are similarly reflected in hub suction surface diffusion. At some expense in increased tip region velocities, contouring the hub-shroud did progressively reduce hub suction surface diffusion.

Boundary 1ayer. - A BLAYER analys is as described previously was done for the three alternate rotor hub-shroud contours. Figure 14 shows the resulting separated region for contours $A, B$, and $C$ superimposed on the baseline results from Fig. 4. The extent of the separation can be seen to be progressively reduced. While contour $C$ had the smallest region of separated flow, it was never entirely eliminated. Although there was some increased diffusion in the tip region, especially for contour $C$, none of the alternate contours showed separation in the tip region.

Estimated losses. - For completeness, Table II presents the loss analys is results. Losses are tabulated in terms of kinetic energy loss coefficients and total-to-total efficiency. The bottom of the table also includes the specific work and some pertinent pressure ratios for each rotor configuration. The stage efficiency numbers represent uncooled values. A constant-area exhaust duct was included in the analysis because the baseline design had been done for a mixed-out downstream plane. The stator loss coefficients are constant for each configuration, but, because stage pressure ratio varied slightiy, the efficiency decrement due to the stator varied also. Although the overa 11 rotor loss coefficients progressively decreased from baseline through contour $C$, the accompanying increasing pressure ratios produced negligible differences in overall efficiency. The results in Table II are for the average of the two reference secondary loss correlations. Using Dunham's correlation alone resulted in about one-half point lower efficiencies.

\section{Conclusions}

Hub-shroud contouring did reduce the estimated extent of the flow separation in a radial rotor. The particular hub-shroud geometries illustrated do not represent an exhaustive attempt to optimize a radial turbine design. Rather, the calculation demonstrates a first step of a systematic approach to radial turbine design using a quasi-3D approach. The significance is that the analysis relies minimally on past experience and can be used to identify and control the aerodynamic characteristics that ultimately determine heat transfer and affect component life. Experimentation will be required to assess the extent to which the analysis predicts the correct flow aerodynamics and boundary layer behavior. 


\section{References}

1. Balje, 0. E., "A Study on Design Criteria and Matching of Turbomachines: Part A - Similarity Relations and Design Criteria of Turbines," Transactions of the ASME, Journal of Engineering for Power, Vo. 84, No. I, Jan. 1962, pp. 83-102.

2. Benson, R. S., "On-Design Performance Characteristics of Radial Gas Turbines," Israel Journal of Technology, Vol. 9, No. 4, 1971, pp. 363-379.

3. Watanabe, I., Ariga, I., and Mashimo, T. "Effect of Dimensional Parameters of Impellers on Performance Characteristics of a RadialInflow Turbine," Transactions of the ASME, Journal of Engineering for Power, Vol. 93, No. 1, Jan. 1971, pp. 81-102.

4. Mizumachi, N., Endo, T. and Kitano, M., "A Study of Aerodynamic Characteristics of Rotating Blades in a Radial Inflow Turbine," Proceedings of the Tokyo Joint International Gas Turbine Conference and Products Show, Japan Society of Mechanical Engineers, Tokyo, 1971, pp. 49-56.
5. Boyle, R. J., Haas, J. E., and Katsanis, T., "Comparison Between Measured Turbine Stage Performance and the Predicted Performance Using Quasi-30 Flow and Boundary Layer Analyses," NASA TM-83640, 1984.

6. Stewart, W. L., "Analys is of Two-Dimensional Compressible-Flow Loss Characteristics Downstream of Turbomachine Blade Rows in Terms of Basic Boundary-Layer Characteristics," NACA TN-3515, 1955.

7. Dunham, J., "A Review of Cascade Data on Secondary Losses in Turbines," Journal of Mechanical Engineering Science, VoT. 12, Feb. 1970 , pp 48-59.

8. Morris, A. W. H. and Hoare, R. G., "Secondary Loss Measurements in a Cascade of Turbine Blades with Meridional Wall Profiling," ASME Paper 75-WA/GT-13, Nov. 1975.

9. Futral, S. M., Jr. and Holeski, D. E., "Experimental Resuits of Varying the BladeShroud Clearance in a 6.02-Inch Radial-Inflow Turbine," NASA TN D-5513, 1970.

10. Wiesner, F. J., "A Review of Si ip Factors for Centrifugal Impellers, "Transactions of the ASME, Journal of Engineering for Power, VoT. 89, Oct. 1967, pp. 558-566. 
TABLE I. - TURBINE DESIGN CONDITIONS

Inlet total temperature, K . . . . . 1607 Inlet total pressure, $\mathrm{N} / \mathrm{m}^{2} \ldots \ldots 1.637 \times 10^{6}$ Specific work, J/g ......... 464.9 Work factor ........... 1.0 Rotor tip speed, $\mathrm{m} / \mathrm{s} \ldots \ldots . . . .682 .8$ Rotor tip diameter, m ....... 0.2038 Rotative speed, rpm......... 64000 Mass flow rate, $\mathrm{kg} / \mathrm{sec} . . . . . .2 .370$ Power, kW ................ 1102 
TABLE II. - ESTIMATED LOSSES

\begin{tabular}{|c|c|c|c|c|c|c|c|c|}
\hline \multirow[b]{3}{*}{$\begin{array}{l}\text { Stator losses } \\
\text { Profile and mixing } \\
\text { Endwall friction } \\
\text { Vaneless space } \\
\text { Secondary } \\
\text { Incidence }\end{array}$} & \multicolumn{2}{|c|}{ Baseline } & \multicolumn{2}{|c|}{ Contour A } & \multicolumn{2}{|c|}{ Contour B } & \multicolumn{2}{|c|}{ Contour C } \\
\hline & $\bar{e}$ & $\Delta n_{t-t}$ & $\overline{\mathrm{e}}$ & $\Delta n_{t-t}$ & $\overline{\mathrm{e}}$ & $\Delta n_{t-t}$ & $\overline{\mathrm{e}}$ & $\Delta n_{t-t}$ \\
\hline & $\begin{array}{r}0.0187 \\
.0165 \\
.0127 \\
.0227 \\
0 . \\
0.0706\end{array}$ & 0.0332 & $\begin{array}{c}\text { Same } \\
\text { as } \\
\text { baseline }\end{array}$ & 0.0309 & $\begin{array}{c}\text { Same } \\
\text { as } \\
\text { baseline }\end{array}$ & 0.0310 & $\begin{array}{c}\text { Same } \\
\text { as } \\
\text { base line }\end{array}$ & 0.0299 \\
\hline $\begin{array}{l}\text { Rotor losses } \\
\text { Profile and mixing } \\
\text { Hub endwall friction } \\
\text { Secondary } \\
\text { Incidence } \\
\text { Tip clearance } \\
\text { Disk friction }\end{array}$ & $\begin{array}{r}0.0666 \\
.0009 \\
.0200 \\
.0528 \\
.1137 \\
.0025 \\
\end{array}$ & $\begin{array}{r}0.0177 \\
.0107 \\
.0231 \\
.0005 \\
\end{array}$ & $\begin{array}{r}0.0530 \\
.0014 \\
.0215 \\
.0393 \\
.0951 \\
.0019 \\
\end{array}$ & $\begin{array}{r}0.0194 \\
.0100 \\
.0242 \\
.0005 \\
\end{array}$ & $\begin{array}{r}0.0501 \\
.0024 \\
.0215 \\
.0396 \\
.0958 \\
.0019 \\
\end{array}$ & $\begin{array}{r}0.0188 \\
.0100 \\
.0243 \\
.0005 \\
\end{array}$ & $\begin{array}{r}0.0524 \\
.0031 \\
.0206 \\
.0346 \\
.0875 \\
.0016 \\
\end{array}$ & $\begin{array}{r}0.0216 \\
.0098 \\
.0248 \\
.0004 \\
\end{array}$ \\
\hline $\begin{array}{l}\text { Total } \\
\text { Exhaust duct }\end{array}$ & 0.2565 & $\begin{array}{l}0.0520 \\
0.0002\end{array}$ & 0.2122 & $\begin{array}{l}0.0541 \\
0.0005\end{array}$ & 0.2113 & $\begin{array}{l}0.0536 \\
0.0004\end{array}$ & 0.1998 & $\begin{array}{l}0.0566 \\
0.0006\end{array}$ \\
\hline Overall uncooled stage eff, $n_{t-t}$ & & .9146 & & 9145 & & 9150 & & 9129 \\
\hline $\begin{array}{l}P_{0}^{1} / P_{1} \\
P_{2}^{\prime \prime}, i d / P_{3} \\
P_{0}^{1} / P_{3}^{1} \\
\text { Specific work, J/g }\end{array}$ & $\begin{array}{r}3 \\
458\end{array}$ & $\begin{array}{l}.881 \\
.324 \\
.49 \\
.5\end{array}$ & $\begin{array}{r}3 . \\
483 .\end{array}$ & $\begin{array}{l}882 \\
455 \\
78 \\
3\end{array}$ & $\begin{array}{r}3 . \\
482 .\end{array}$ & $\begin{array}{l}882 \\
451\end{array}$ & $\begin{array}{r}3 . \\
494 .\end{array}$ & $\begin{array}{l}882 \\
535 \\
94 \\
9\end{array}$ \\
\hline
\end{tabular}




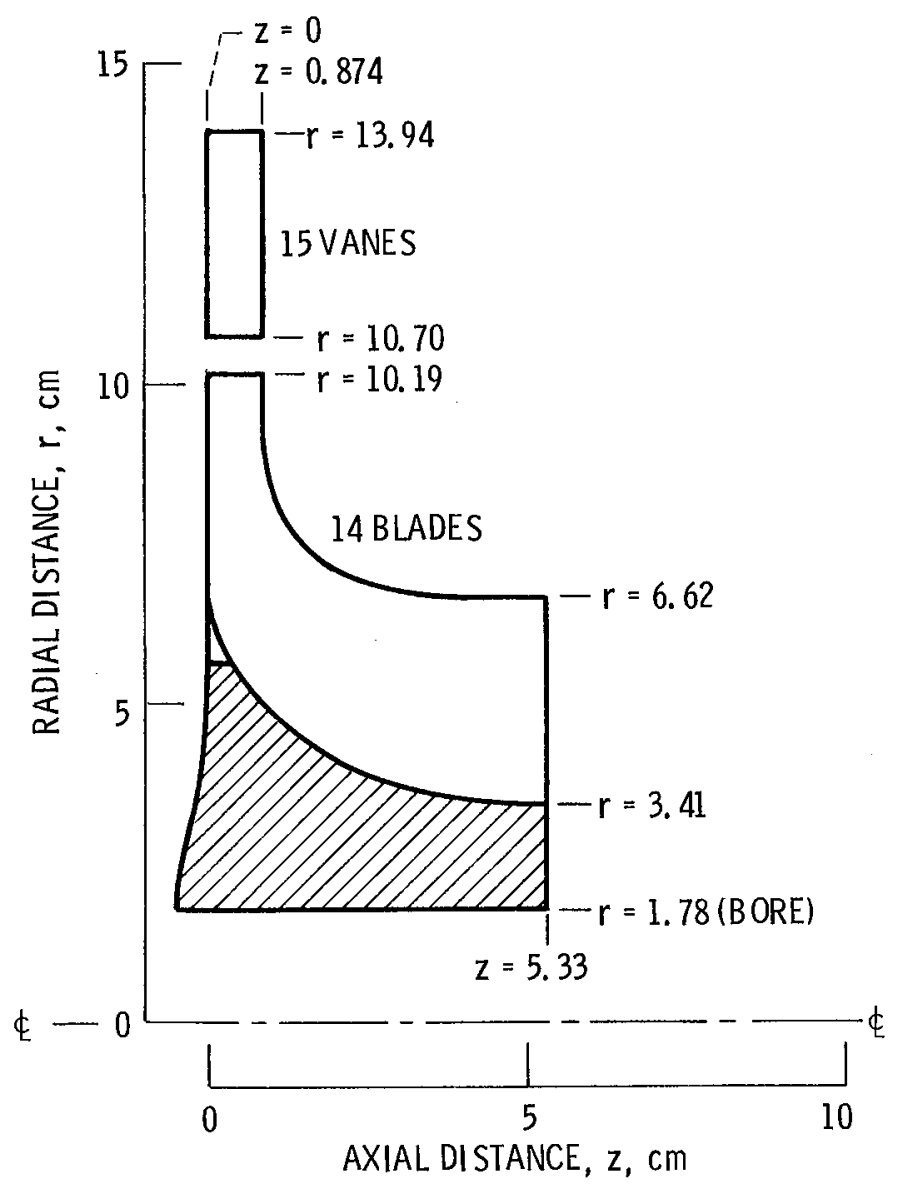

(a) Meridional flowpath.

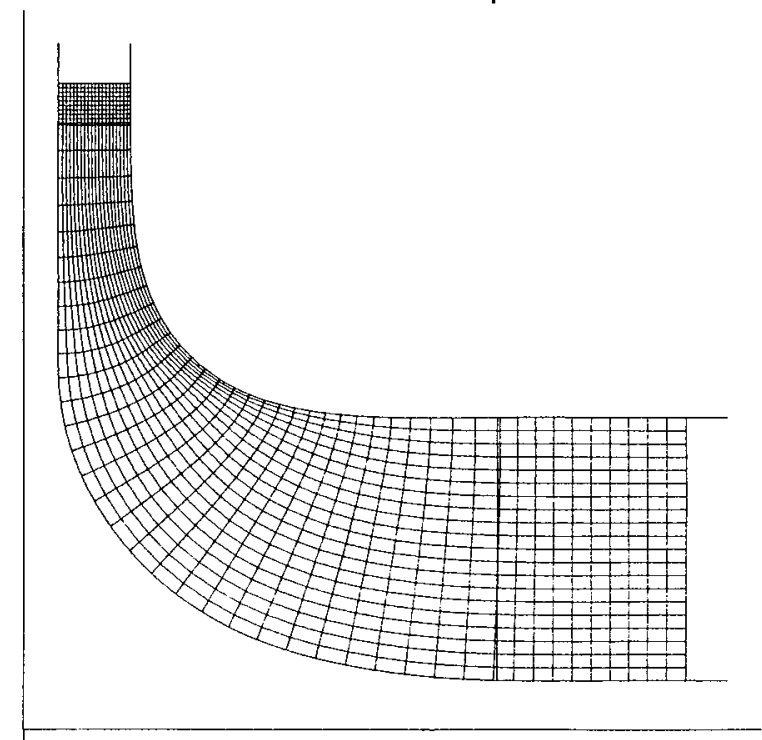

(b) MERIDL mesh

Figure 1. - Baseline radial turbine geometry. 


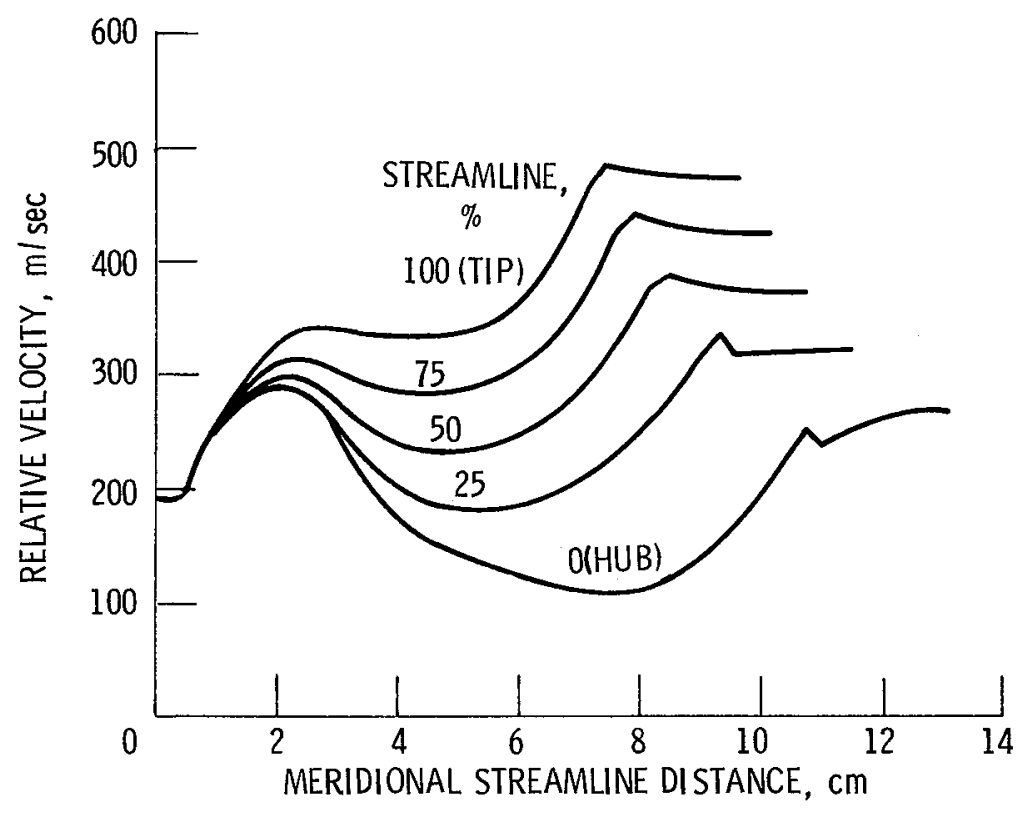

Figure 2. - Relative mid-channel velocities for baseline rotor. 


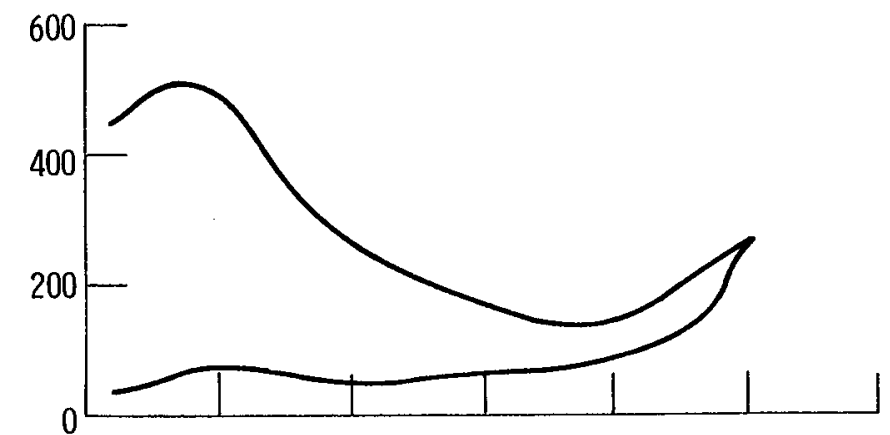

(a) Hub (0\% streamline).

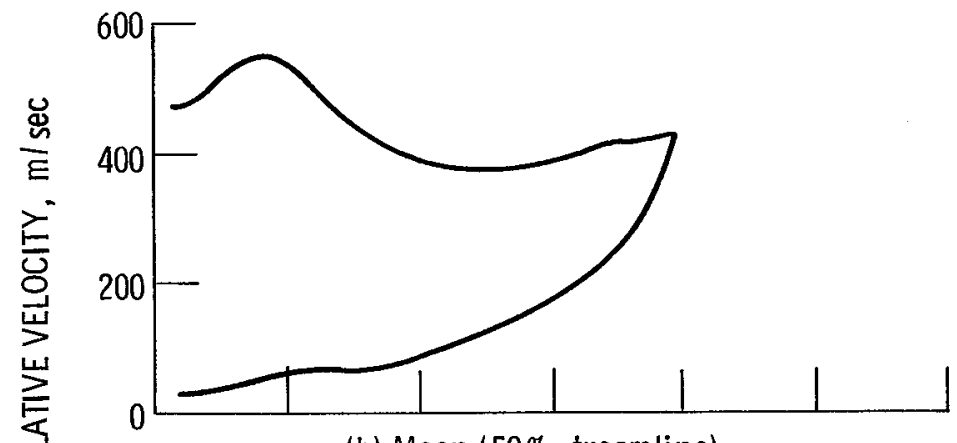

(b) Mean (50\% streamline).

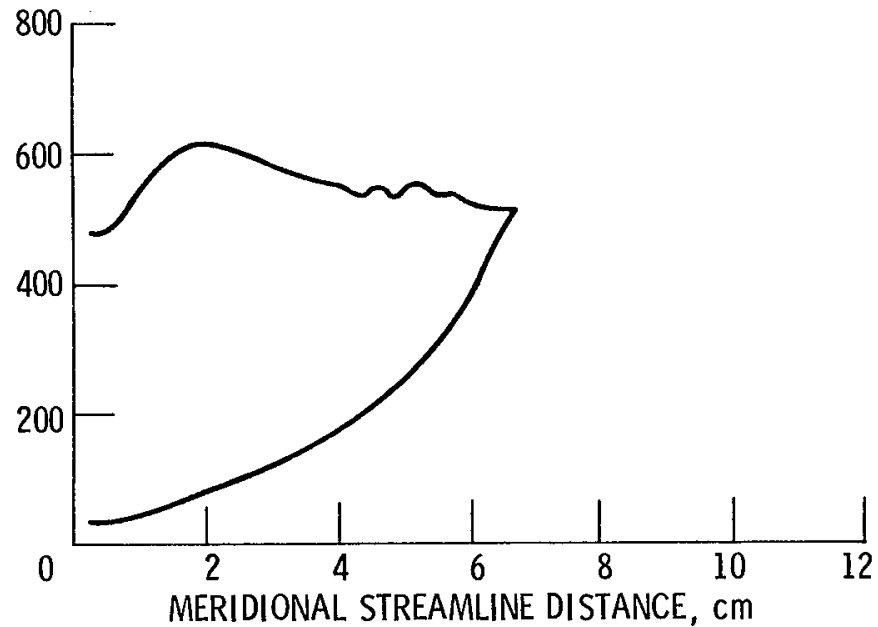

(c) Tip (100\% streamline).

Figure 3. - Relative blade surface velocities for baseline rotor. 


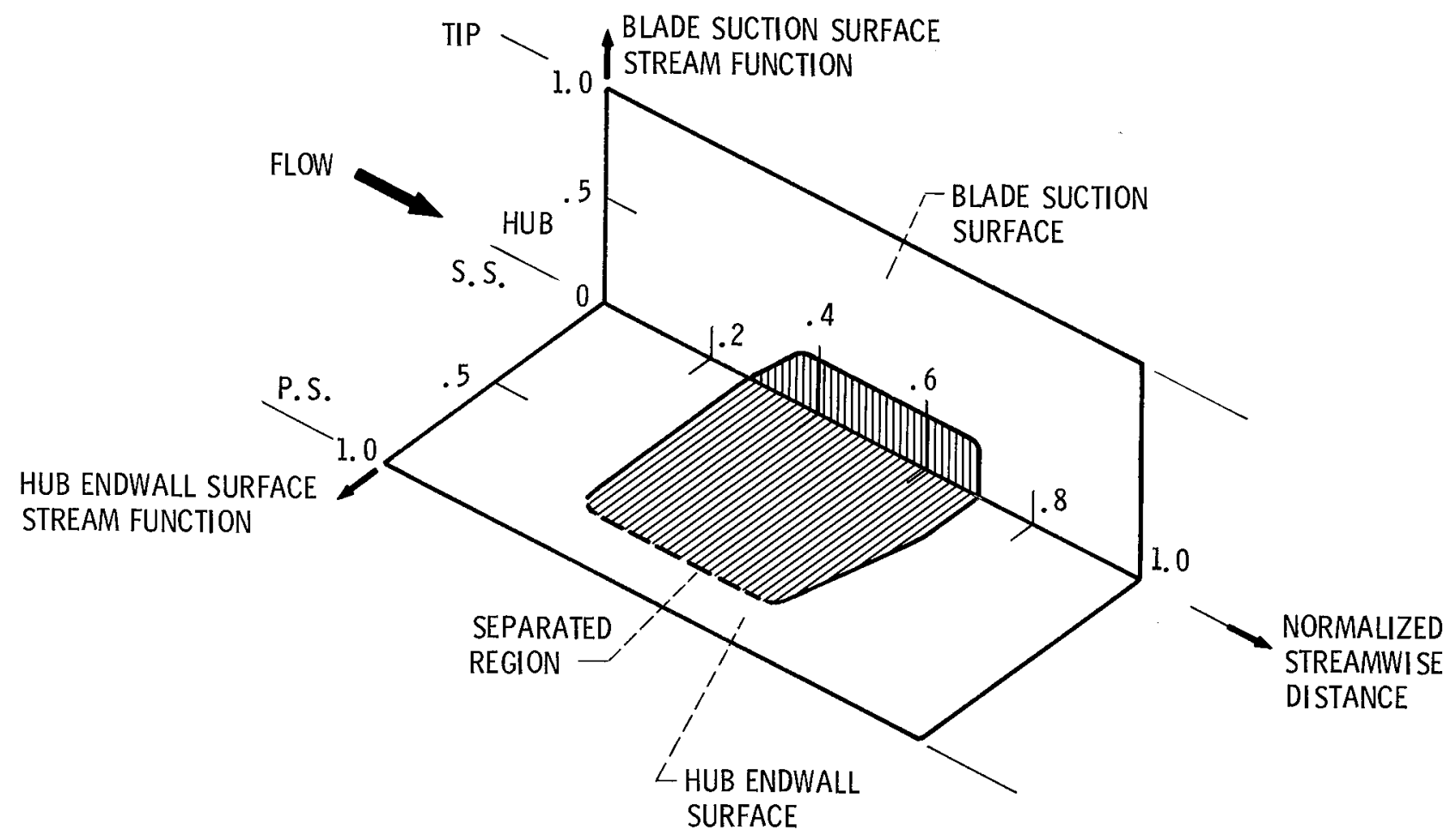

Figure 4. - Extent of separated flow region for baseline rotor. 


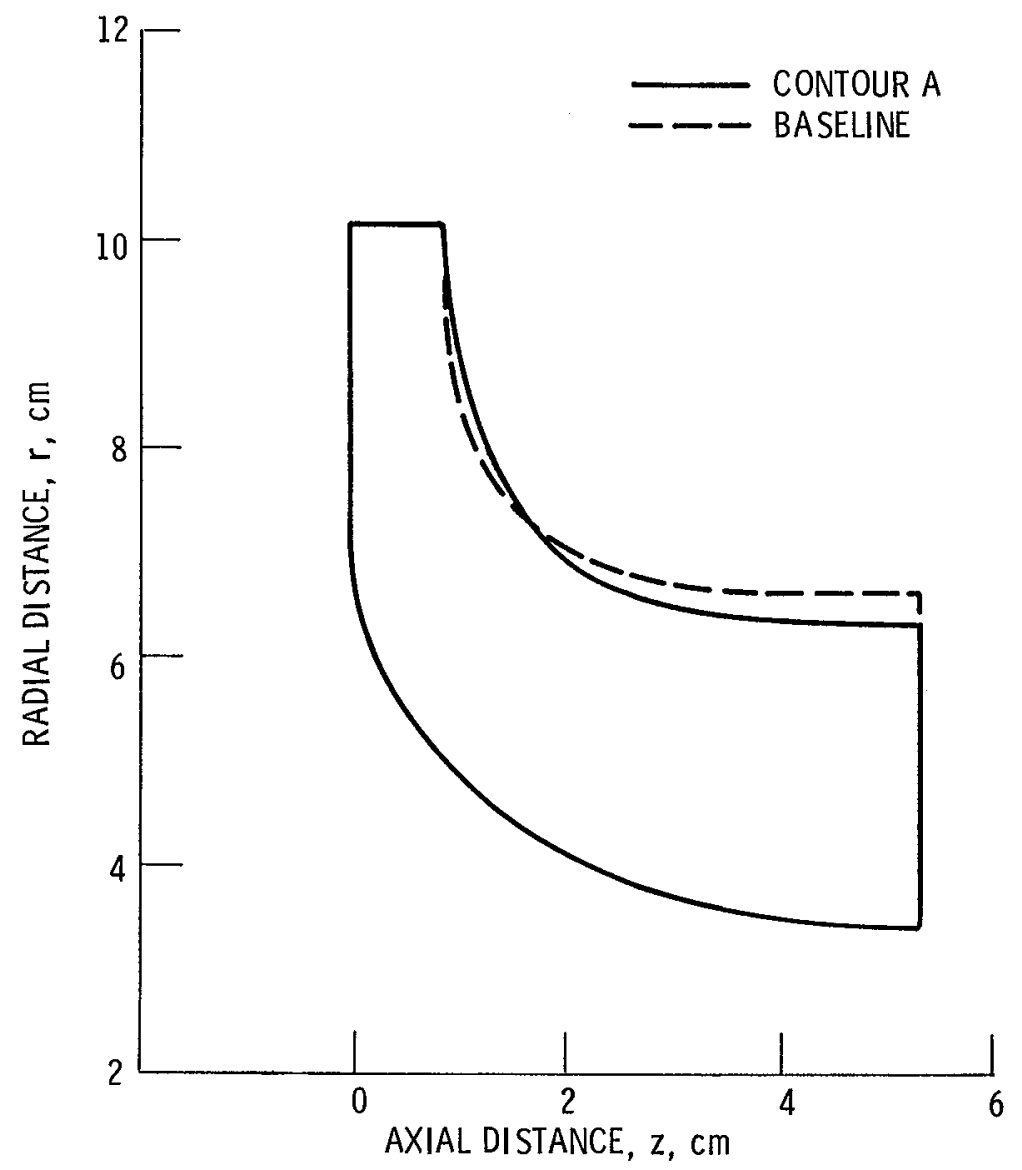

(a) Meridional flowpath.

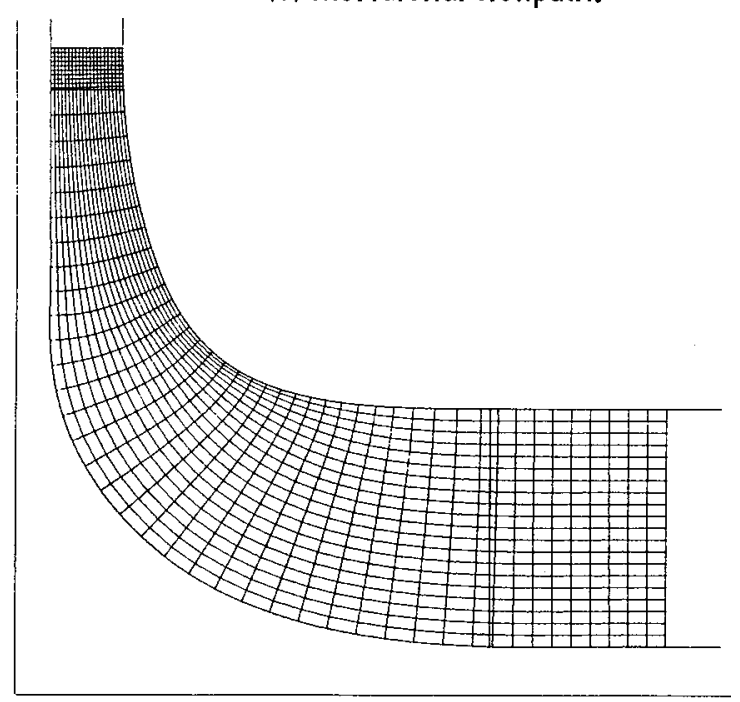

(b) MERIDL mesh.

Figure 5. - Contour A geometry. 

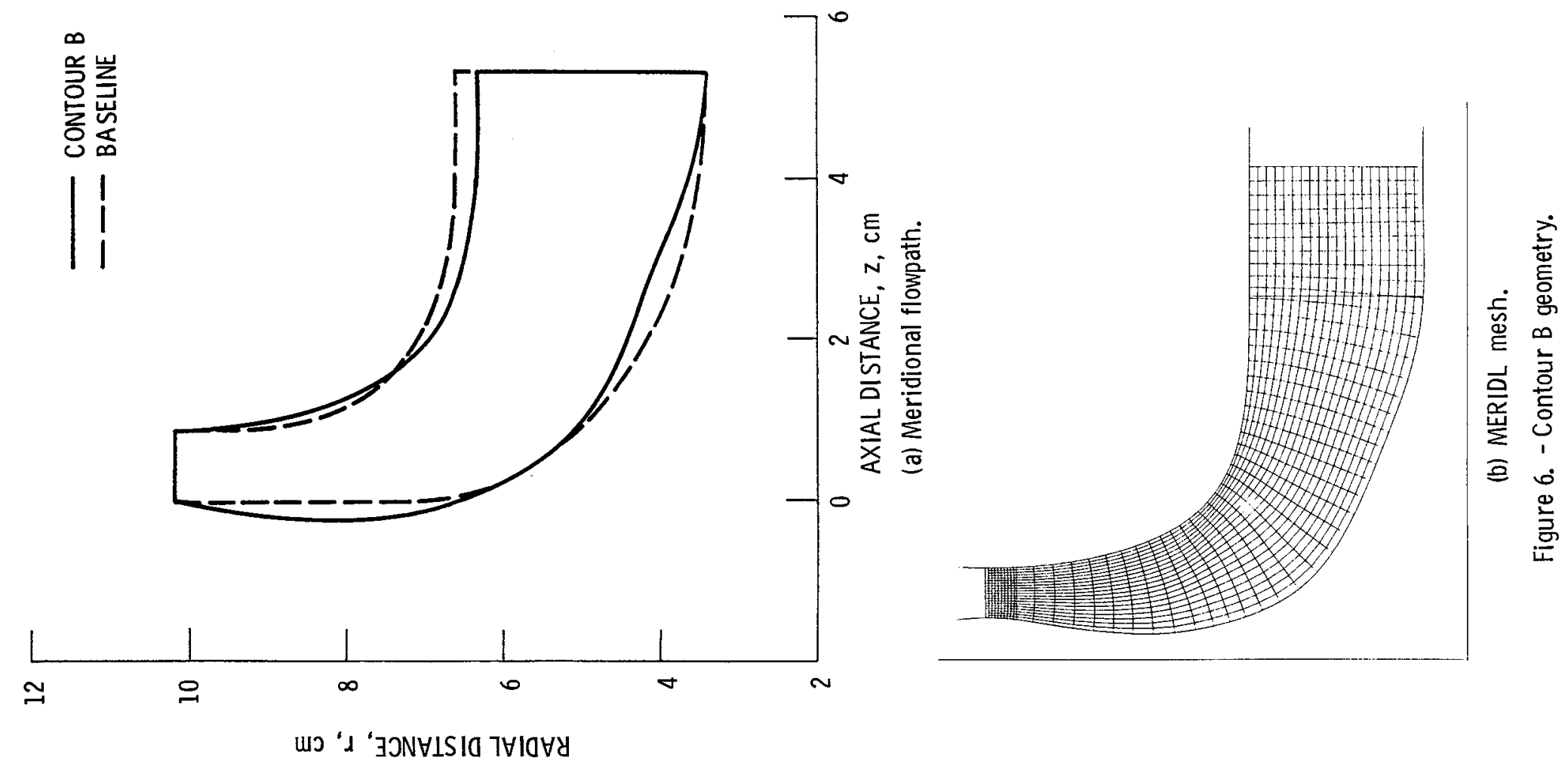


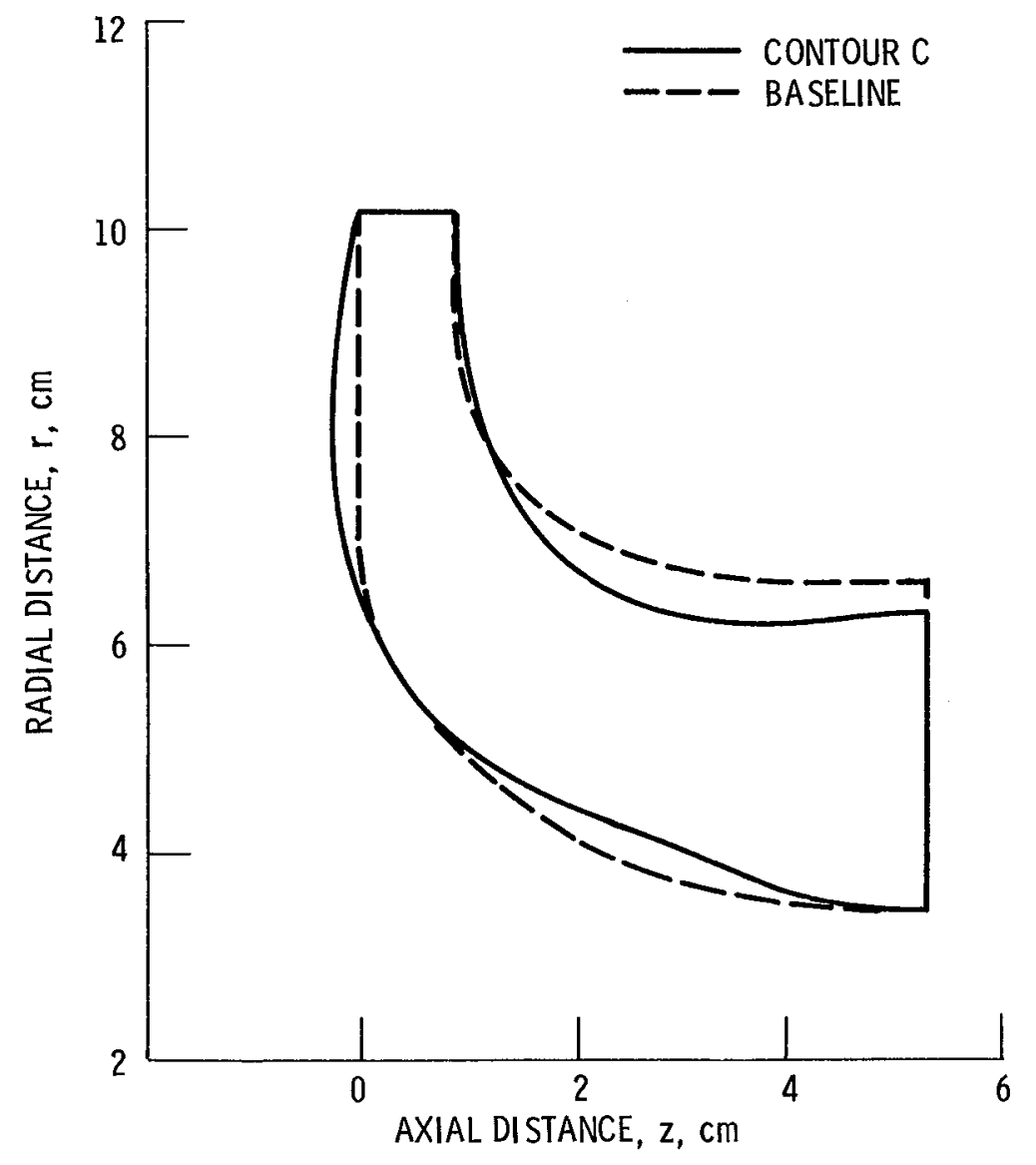

(a) Meridional flowpath.

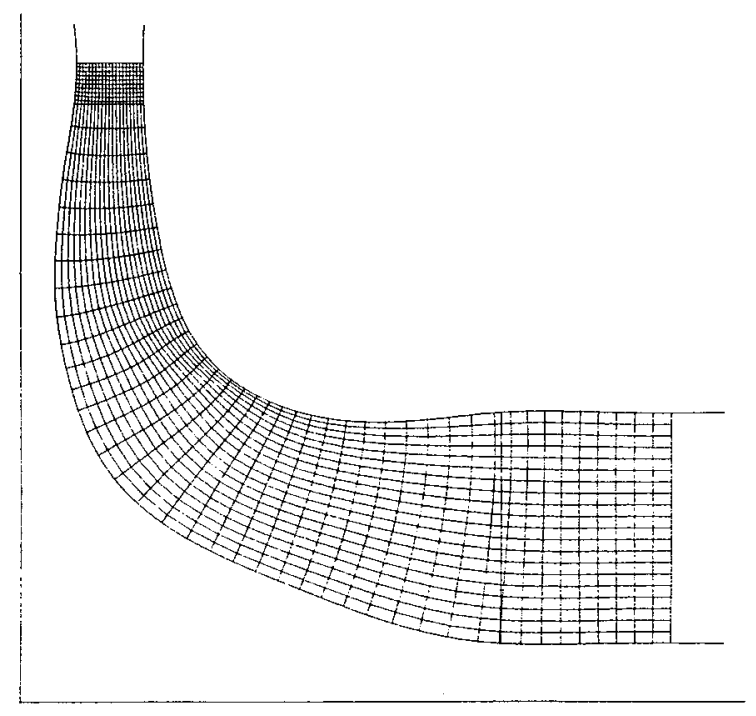

(b) MERIDL mesh.

Figure 7. - Contour $\mathrm{C}$ geometry. 


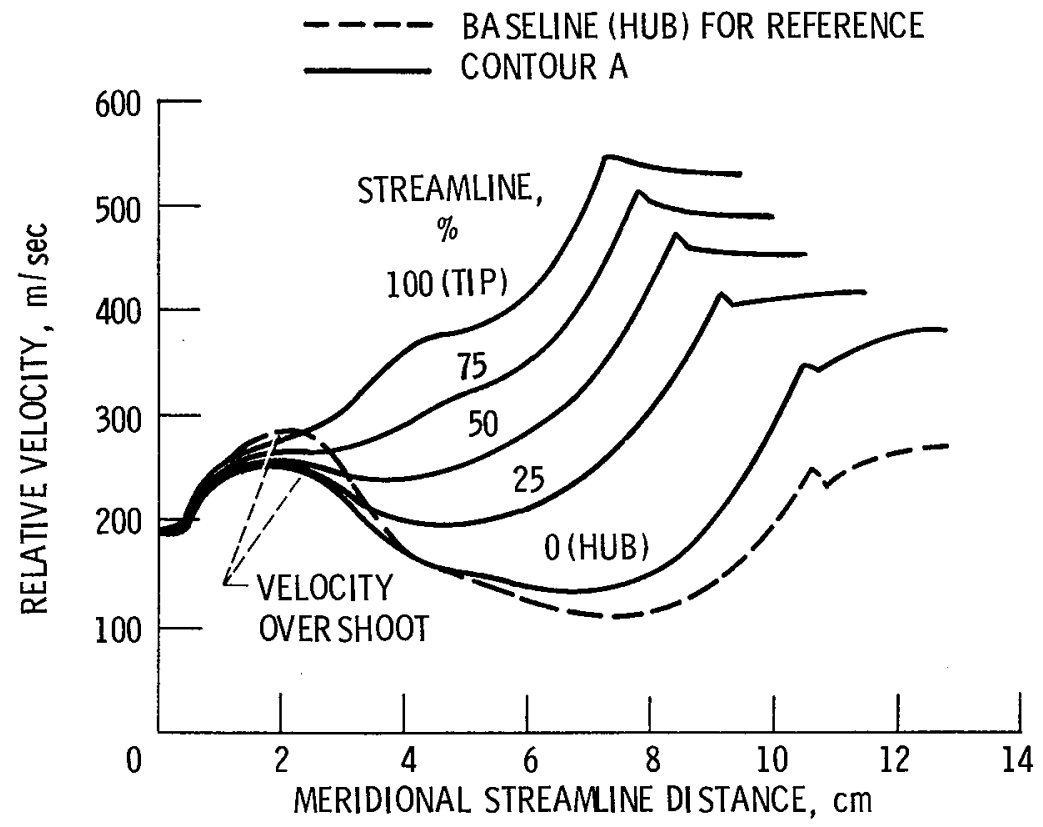

Figure 8. - Relative mid-channel velocities for contour A.

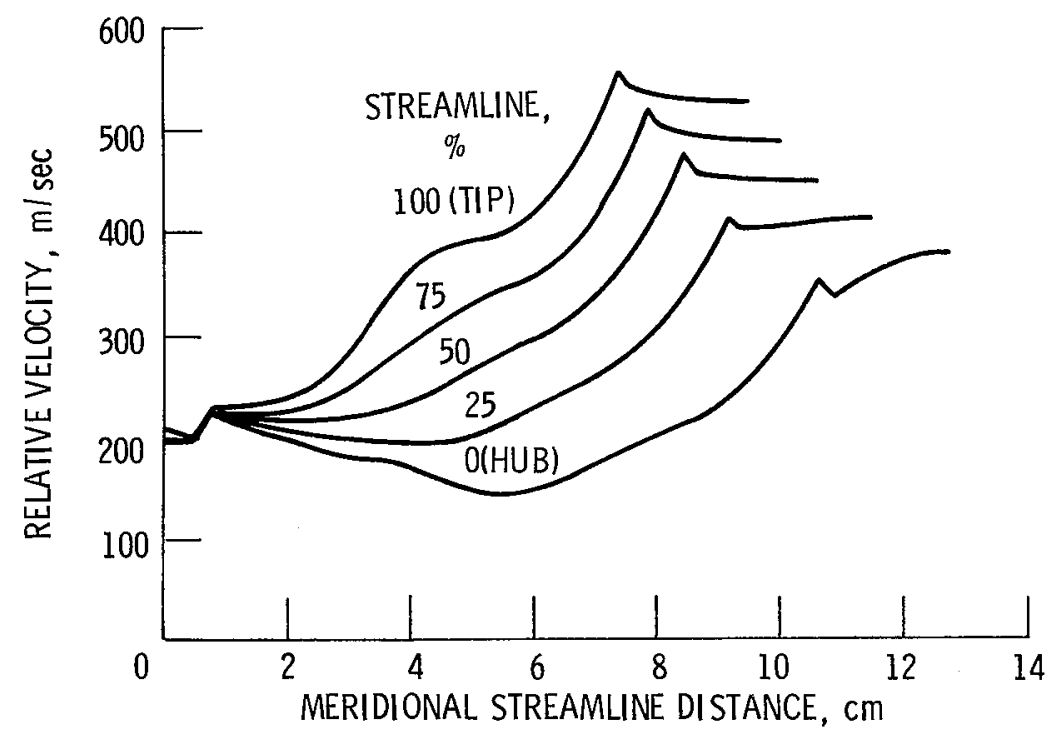

Figure 9. - Relative mid-channel velocities for contour B. 


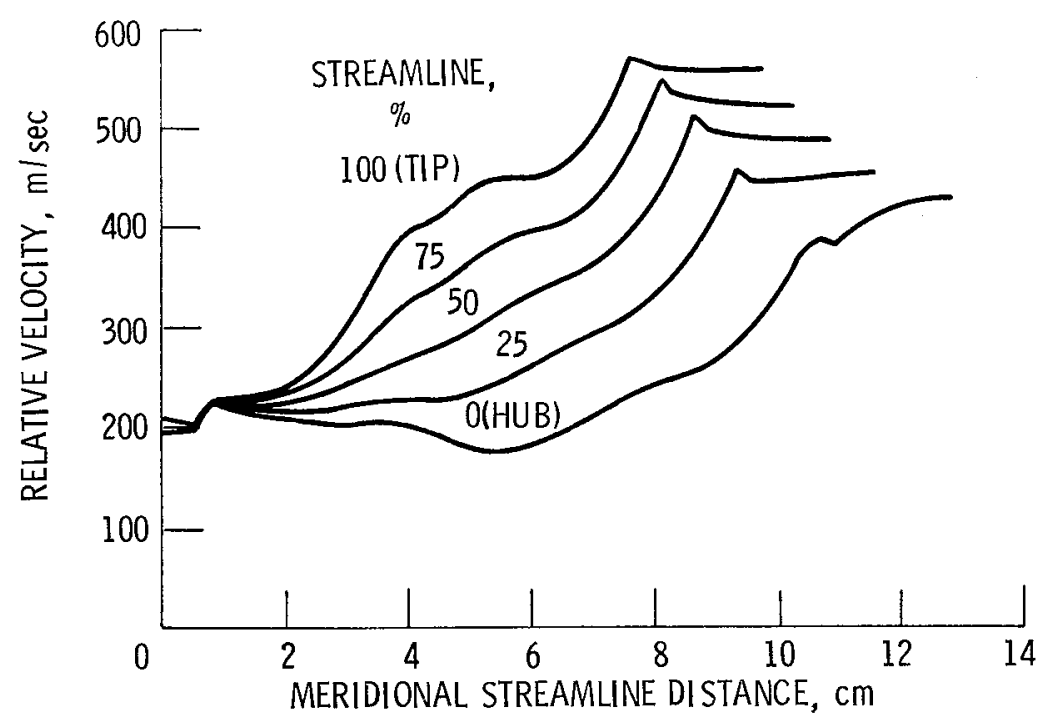

Figure 10. - Relative mid-channel velocities for contour $C$. 


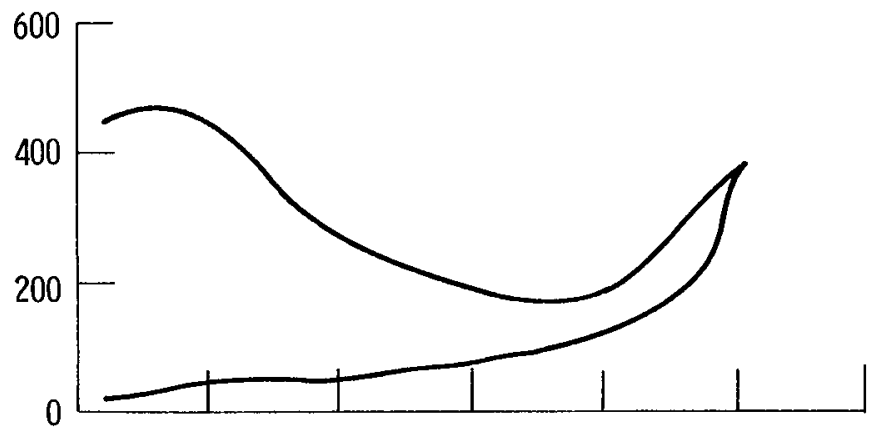

(a) Hub (0\% streamline).

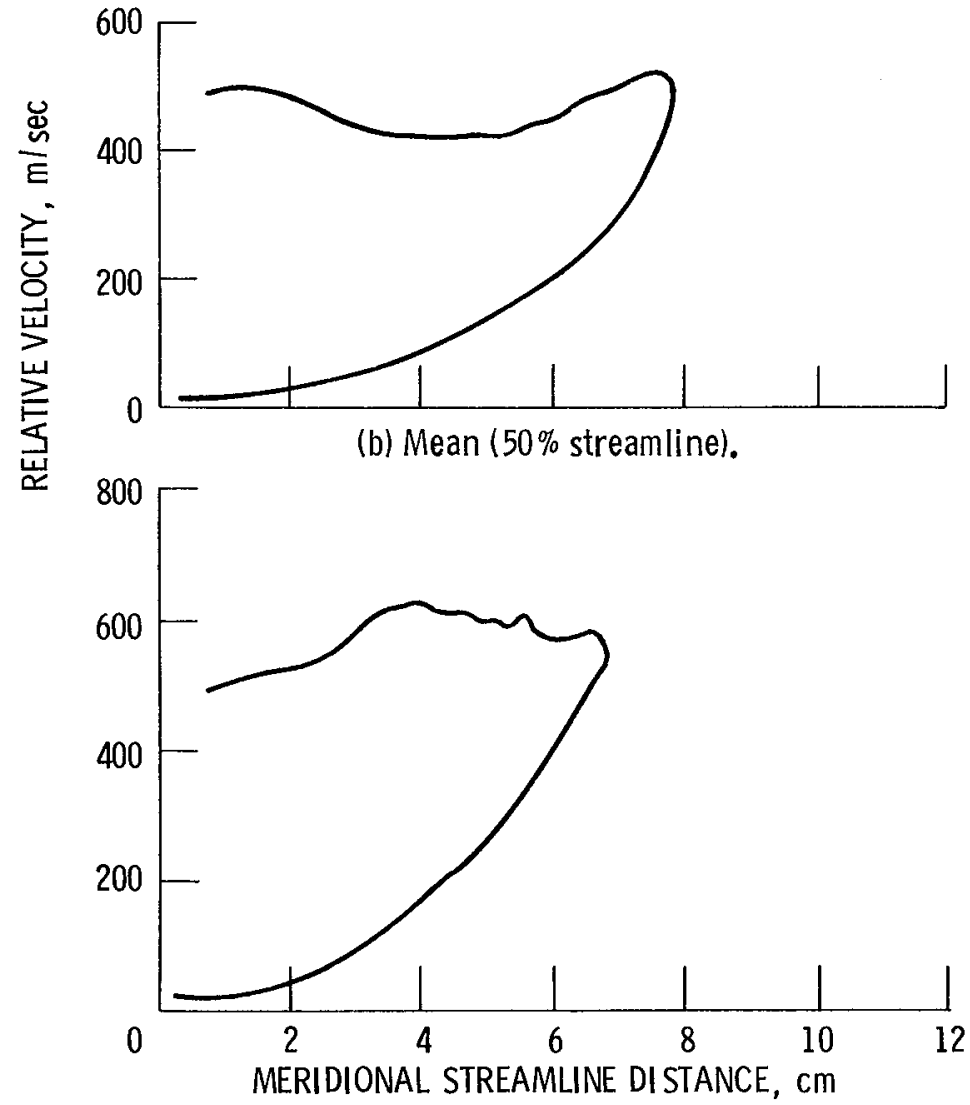

(c) Tip ( $100 \%$ streamline)

Figure 11. - Relative blade surface velocities for contour $A$. 


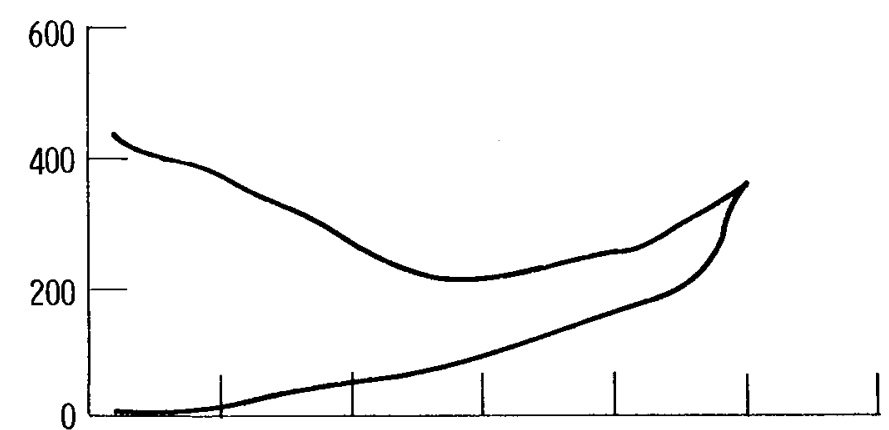

(a) Hub (0\% streamline).

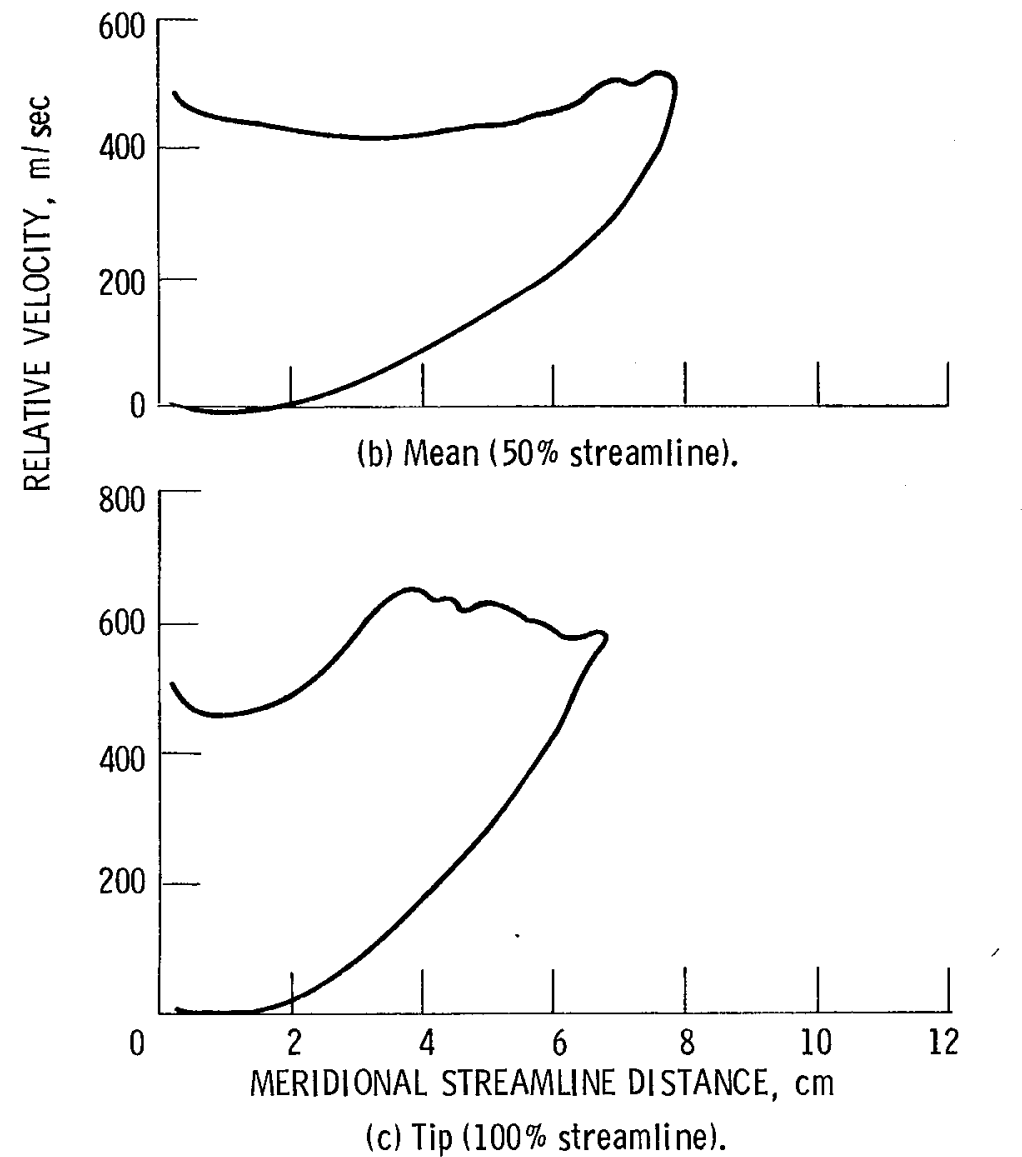

Figure 12. - Relative blade surface velocities for contour B. 


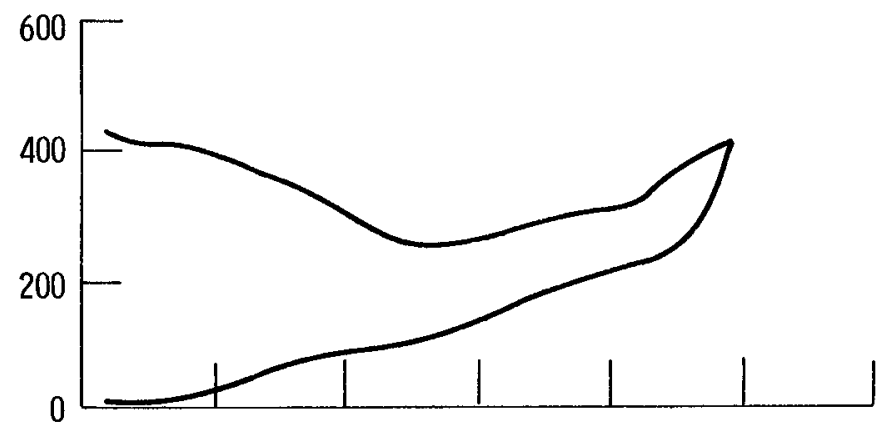

(a) Hub (0\% streamline).

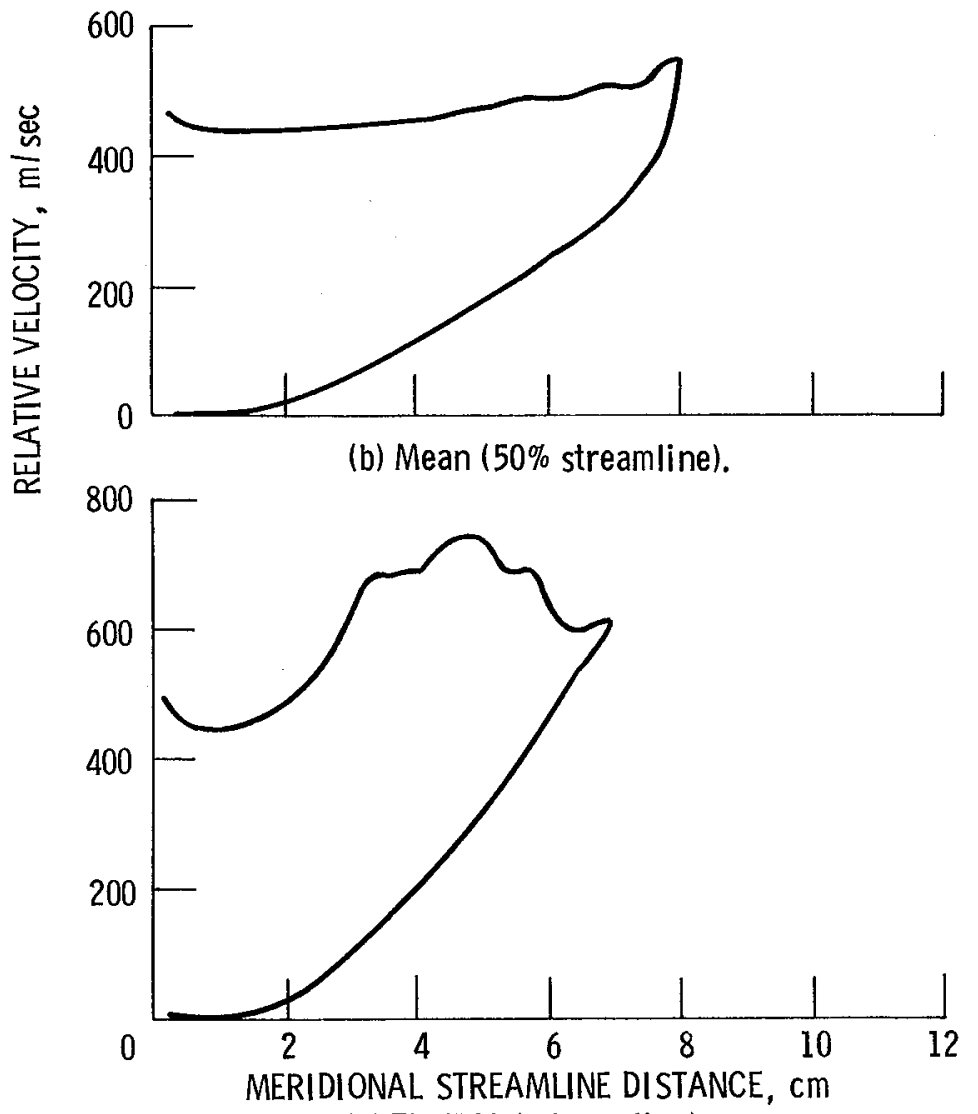

(c) Tip (100\% streamline).

Figure 13. - Relative blade surface velocities for contour C. 


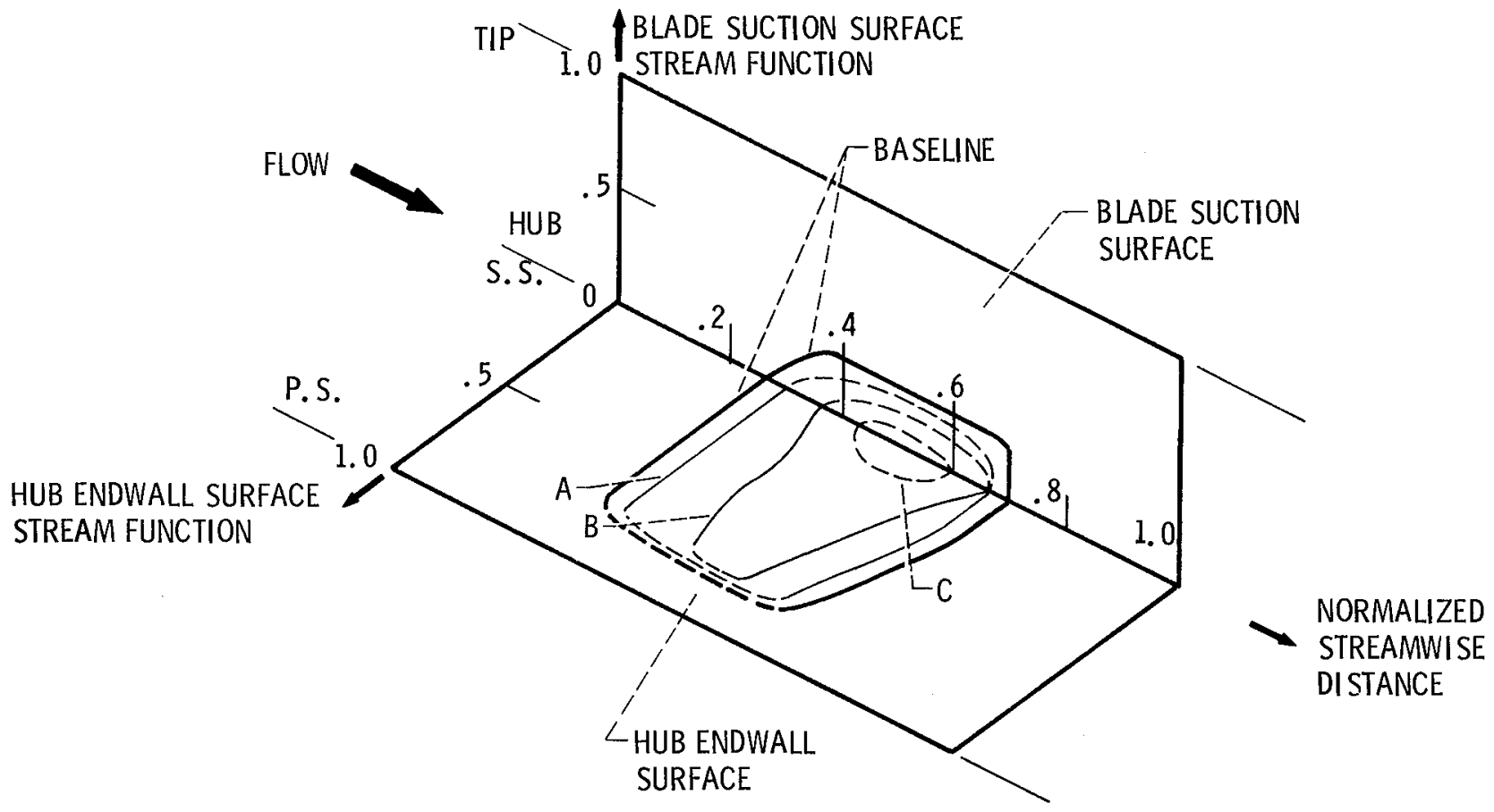

Figure 14. - Extent of separated flow region for baseline and contoured hub-shroud rotors. 


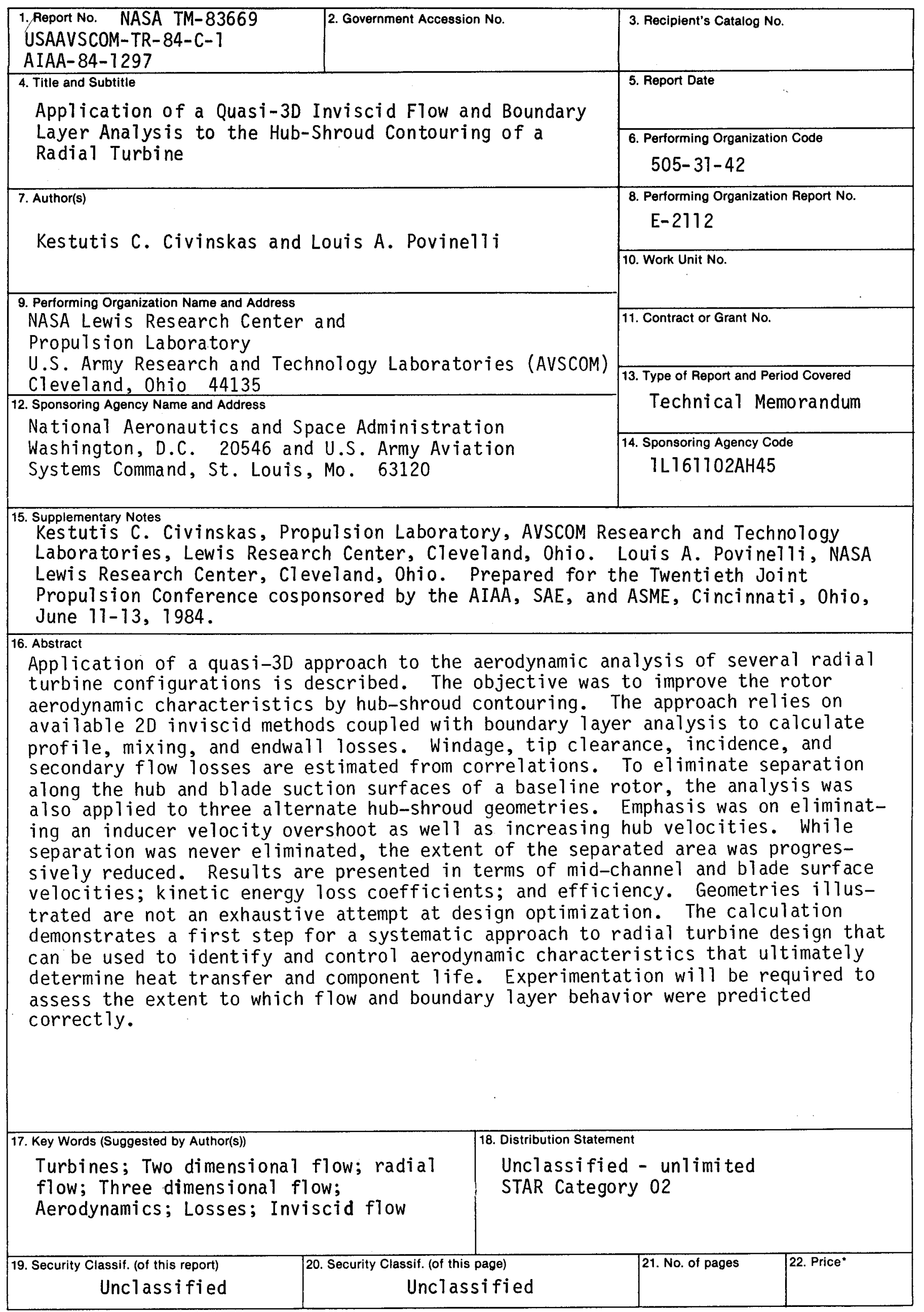

*For sale by the National Technical Information Service, Springfield, Virginia 22161 